\title{
PERCEPÇÃO DAS PROBLEMÁTICAS SOCIOAMBIENTAIS DO RIO DA CHATA NO MUNICÍPIO DE JUPI (PE)
}

\author{
Macelle Soares Almeida Silva ${ }^{(a)}$, Jeovanes Lisboa da Silva Filho ${ }^{(b)}$, Suzana de Araújo Silva ${ }^{(c)}$ \\ (a) Graduanda em Geografia pela (UPE), Campus Garanhuns, E-mail: macelle_soares@hotmail.com \\ (b) Graduando em Geografia pela (UPE), Campus Garanhuns, E-mail: jeovanelisboa @ hotmail.com \\ ${ }^{(c)}$ Doutoranda em Meio Ambiente e Desenvolvimento (UFPE).E-mail: suzana.araujo.upe@ hotmail.com
}

\section{EIXO: BACIAS HIDROGRÁFICAS E RECURSOS HÍDRICOS: ANÁLISE, PLANEJAMENTO E GESTÃO}

\begin{abstract}
Resumo
Apresenta-se o referido trabalho, o qual tem como objetivo identificar as problematicas socioambientais do rio da Chata em Jupi (PE) por meio da percepção. Enquanto metodologia de trabalho, priorizou-se inicialmente a revisão bibliografica, associada com visitas in lo e registos fotograficos, bem como a percepção e a subjetividade dos pesquisadores envolvidos. Quanto aos resultados, observou-se a intensa poluição do rio da Chata, sobretudo pelo fato dos diversos efluentes domesticos por a cidade não dispor de um sistema de saneamento básico eficiente, o que afeta a qualidade de vida da população que reside ao entrono. Para tanto, o trabalho contribuiu para despertar reflexão frente as problematicas sociombietais e suas implicações a população que interage com esse recuros hidrico.
\end{abstract}

Palavras chave: Recursos hídricos. Saneamento básico. Percepção ambiental

\section{Introdução}

O objetivo do presente trabalho é trazer à tona elementos de reflexão referente as problemáticas socioambientais do rio da Chata, especificamente no município de Jupi (PE), por meio da percepção. Entende-se por percepção com base em (OKAMOTO, 1996, p. 200 apud AMADOR, 2013, p. 81) "a compreensão das inter-relações entre o meio ambiente e os atores sociais e como a sociedade percebe o seu meio circundante, expressando suas opiniões, expectativas e propondo linhas de conduta". Ou seja, é quando o sujeito externa o seu ponto de vista. Levar em consideração a percepção é, também, valorizar a cultura, a subjetividade, a história, formação entre outros.

Verifica-se salutar a importância da sustentabilidade do rio em pauta, uma vez que ele é uma importante fonte de abastecimento para o município já citado, servindo também para irrigação das lavouras na área rural. Em seu percurso conta com uma cachoeira, a qual era ponto turismo, onde a população do entorno e visitantes usufruíam como fonte de lazer. No entanto, atualmente não existem mais visitas ao local, em virtude das suas águas estarem poluídas e apresentando-se nocivas aos seres humanos. 


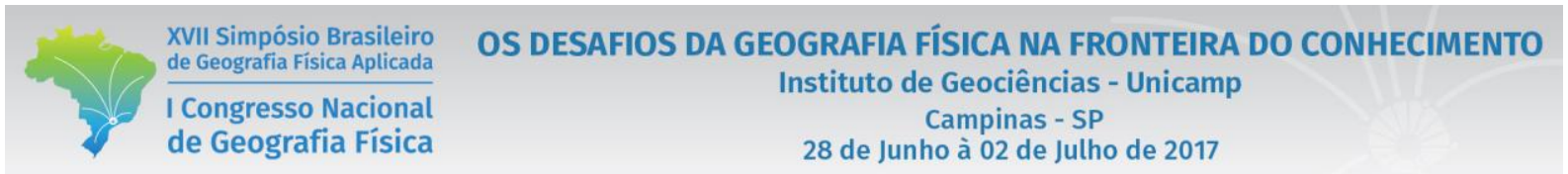

Com relação aos procedimentos metodológicos, inicialmente realizou-se um levantamento bibliográfico para se ter um apoderamento de conhecimento e, consequente amadurecimento de ideias. Foi realizado também, técnicas de observação in loco para identificação de alguns problemas ambientais e registros fotográficos embasando, assim, as considerações aqui traçadas. Para tanto, o método de cunho geográfico adotado neste trabalho foi o fenomenológico, o qual prima pela percepção e subjetividade dos pesquisadores envolvidos frente ao objeto estudado.

\section{2. Área de estudo}

O rio da Chata (Figura 01), perpassa no município de Jupi (PE). Esse município tem um clima que varia do sub úmido ao semiárido, que na literatura geográfica é decorrente da sua localização que está numa área de transição entre a zona fisiografia do Sertão e a Zona da Mata sendo composta por vegetação subcaducifólica e caducifólia.

O município se encontra nos domínios das bacias hidrográficas dos rios Mundaú e Una e têm como um dos principais tributários o rio da Chata. Seu relevo possui características planas e levemente onduladas encontra-se inserido na área central do Planalto da Borborema que se estende do sul de Alagoas ao Rio Grande no Norte.

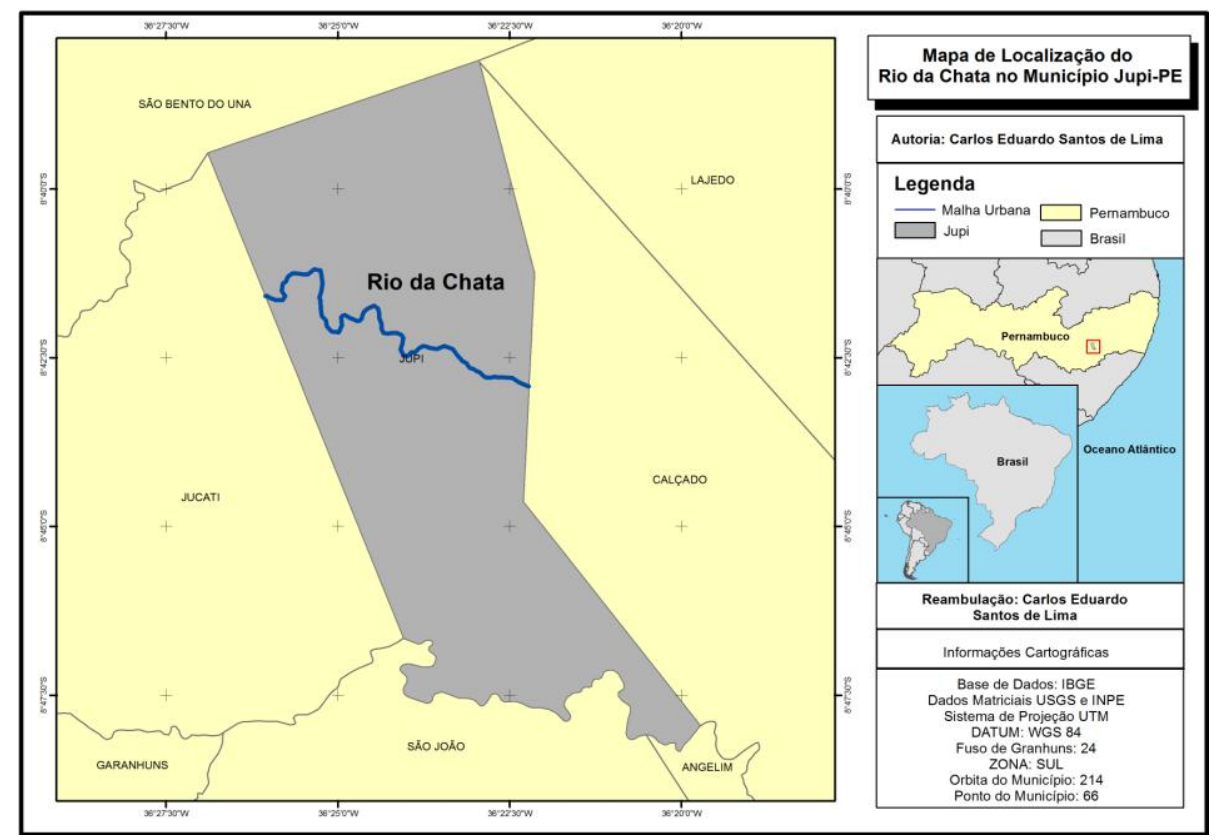

Figura 01 - Localização do rio da Chata em Jupi (PE). Fonte: adaptado por Lima, (2017) 
XVII Simpósio Brasileiro

de Geografia Física Aplicada

I Congresso Nacional

de Geografia Física
OS DESAFIOS DA GEOGRAFIA FÍSICA NA FRONTEIRA DO CONHECIMENTO

Instituto de Geociências - Unicamp

Campinas - SP

28 de Junho à 02 de Julho de 2017

O rio da Chata é um dos principais afluentes para o rio Una, o qual possui nascente no município de Capoeiras, apresentando-se intermitente até aproximadamente a cidade de Altinho, quando se torna perene, detendo sua foz em São José da Coroa Grande (PE). No verão não dispõe de água (Figura B), o que resta para seguir o percurso são os efluentes despejados sem tratamento algum, o que contribui para severos impactos de ordem ambiental.

\section{Fundamentos Teóricos}

Sabendo-se da relevância do recurso hídrico para a sociedade em geral, sem esquecer dos animais e outros seres viventes, criveis ou não. Trazemos à tona Leal (2000), o qual enfatiza que a água é o sangue da terra, é insubstituível. Nada é mais suave e, nada a ela resiste. Já a Lei 7.663/91 realça que água é um recurso natural essencial a vida, ao desenvolvimento econômico e ao bem estar social.

Dessa forma, é importante que se planeje medidas que visem a sustentabilidade deste recurso. A sustentabilidade de acordo com o conceito da Comissão Mundial sobre o Meio Ambiente e Desenvolvimento (1998), em seu relatório intitulado "Nosso Futuro Comum" é aquele desenvolvimento que utiliza os recursos naturais sem comprometer a capacidade das gerações futuras atenderem as suas necessidades.

Pata tanto, o saneamento básico é um importante instrumento que evita a poluição de recursos hídricos superficiais e subterrâneos. Para Kobiyama (2008), o saneamento é um conjunto de medidas que promovem níveis crescentes de salubridade e suas condições resultantes. Ainda sobre a classificação do que venha ser saneamento, o Plano Nacional do Meio Ambiente diz que: com o advento da Lei $\mathrm{n}^{\circ}$ 11.445/07, foi cunhado o conceito de saneamento básico como o conjunto de serviços, infraestruturas e instalações de abastecimento de água, esgotamento sanitário, limpeza urbana e manejo de resíduos sólidos e drenagem de águas pluviais urbanas. Já Silva (2014), enfatiza que:

O saneamento deve ser entendido como um instrumento essencial para o desenvolvimento urbano e qualidade de vida. A OMS cita que saneamento é o controle de todos os meios físicos do homem, que exercem ou podem exercer efeito prejudicial ao seu bem estar físico, mental ou social. (SILVA, 2014, p. 19).

Pois, quando ocorre o lançamento sem tratamento (in natura) de esgoto doméstico nos corpos de água, há prejuízos à qualidade da água, com alteração de seu aspecto visual, redução da concentração de oxigênio dissolvido na água, o que dificulta a sobrevivência dos seres de vida aquática, além da presença de gases com mau cheiro e da possibilidade de contaminação humana e animal devido ao consumo/contato com a água (SARDINHA et al., (2008) apud Rizk et al., (2016). 
XVII Simpósio Brasileiro

de Geografia Física Aplicada

I Congresso Nacional

de Geografia Física
OS DESAFIOS DA GEOGRAFIA FÍSICA NA FRONTEIRA DO CONHECIMENTO

Instituto de Geociências - Unicamp

Campinas - SP

28 de Junho à 02 de Julho de 2017

Ressalta-se a relevância da educação e gestão ambiental a nível municipal, as quais venham associadas ao planejamento estratégico por parte do setor público, privado, associações entre outros interessados no plano e gestão de recurso hídrico. Mas, é necessário atentar-se para a Lei das Águas (Lei Federal $\mathrm{n}^{\circ}$ 9.433/1997), pois os planos de recursos hídricos constituem planos diretores que visam a fundamentar e orientar a implementação da Política Nacional de Recursos Hídricos, os quais devem ser de longo prazo, permitindo a execução dos programas e projetos estabelecidos e a consecução dos objetivos propostos de forma participativa, descentralizada e democrática.

\section{Resultados}

Verificou-se que o município de Jupi (PE) apresenta um déficit em relação ao saneamento básico, por consequência desencadeia um conjunto de problemáticas socioambientais, devido ao fato de que o saneamento vem a ser a estrutura que possibilita o desenvolvimento da localidade de maneira sustentável e harmonioso com os recursos hídricos existentes.

De acordo com alguns funcionários do projeto de saneamento da cidade já citada, na zona urbana do município cerca de 1.320 residências têm seus efluentes domésticos direcionados para o rio da Chata (Figura A). Aproximadamente 60 mil litros de efluentes são liberados diariamente no corpo receptor. O que evidencia a poluição dos recursos hídricos. Entende-se por poluição Segundo (BRASIL, 1981), a Lei 6.938 de 31 de agosto de 1981, que dispõe sobre a Política Nacional do Meio Ambiente, dá a seguinte definição para poluição:

é "[...] a degradação da qualidade ambiental resultante de atividades que direta ou indiretamente: a) prejudiquem a saúde, a segurança e o bem-estar da população; b) criem condições adversas às atividades sociais e econômicas;

c) afetem desfavoravelmente a biota; d) afetem as condições estéticas ou sanitárias do meio ambiente; e) lancem matérias ou energia em desacordo com os padrões ambientais estabelecidos $[\ldots] "$.

Verificou que sistema de esgotamento sanitário, quando não eficiente, gera emanação de odores desagradáveis ao olfato ou potencialmente ofensivos e/ou nocivos à saúde e ao meio ambiente. Dessa forma, é patente que as problemáticas ambientais, no caso aqui enfatizado da poluição dos recursos hídricos, acarretam sérios riscos à saúde da população seja por meio direto, onde a população interage diretamente com esses recursos hídricos, ou indireto, uma vez que as margens do mesmo encontram-se plantio de variadas frutas, legumes e hortaliças que servem para o abastecimento da população local. 

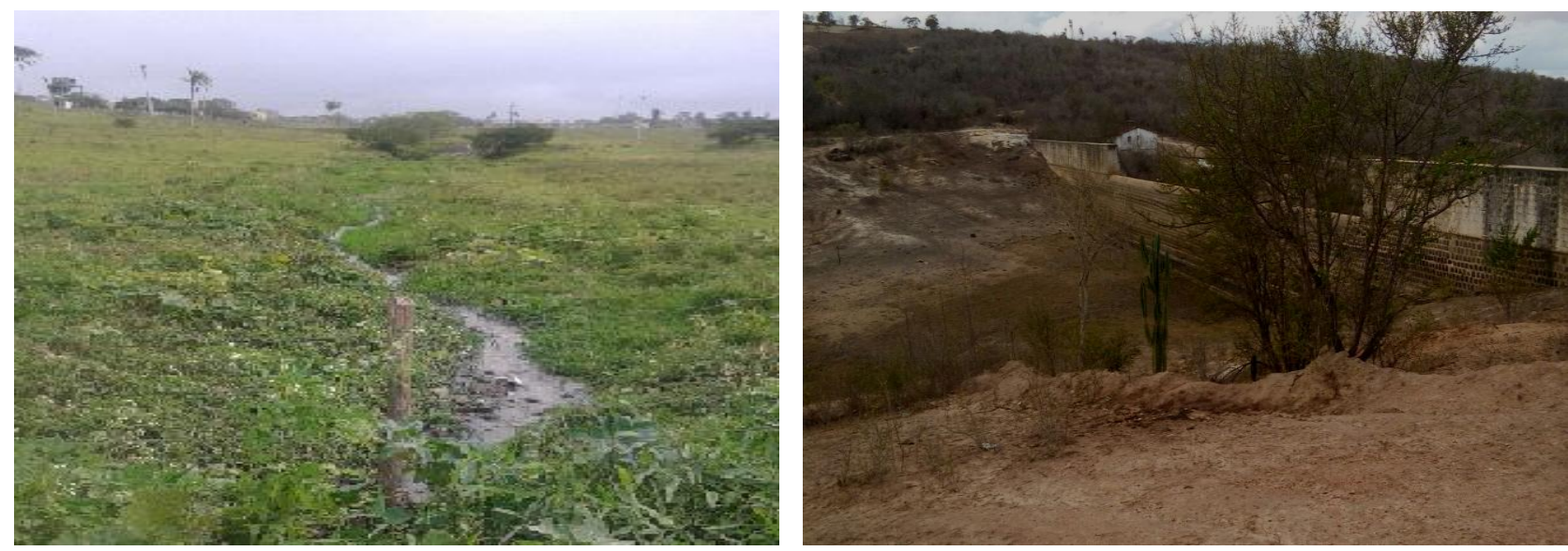

Figura A - Córrego de esgoto que é despejado no rio da chata. Figura B - Rio da Chata em época de seca. Fonte: Silva (2017)

Observou-se também, alguns animais ao entorno, ao quais acreditamos serem criações que mais tarde serviram para abate e consumo. Assim, evidencia-se a importância de um planejamento relacionado aos recursos hídricos do rio em questão por meio de um plano de recursos hídricos que é um instrumento de planejamento contínuo e dinâmico, numa visão de longo prazo, de forma a permitir uma gestão compartilhada do uso múltiplo e integrado dos recursos hídricos.

\section{Considerações Finais}

Em termos de considerações finais deste trabalho que objetivou identificar algumas problemáticas socioambientais, por meio da percepção, tendo-se como foco o rio da chata no município de Jupí (PE), foi possível identificar alguns déficits, quando trata-se de saneamento básico, dos quais acarretam problemas direto e indiretamente ligados a saúde e ao bem estar da população que residem nas proximidades, evidenciando, então, uma carência quando trata-se de um planejamento de gestão hídrica por meio dos órgãos públicos municipais

\section{Referências}

AMADOR, Maria Betânia Moreira (Org.) Sistemismo e sustentabilidade: questão interdisciplinar. São Paulo: Scortecci, 2011.

BRASIL. Lei N. 6.938 de 31 de agosto de 1981. Dispõe sobre a Política Nacional do Meio Ambiente, seus fins e mecanismos de formulação e aplicação, e dá outras providências. Disponível em: <http://www.planalto.gov.br/ccivil_03/Leis/L6938.htm〉. Acesso em: 15 fev. 2017.

BRASIL. Lei $n^{\circ}$ 9433, de 8 de janeiro de 1997: Política Nacional dos Recursos Hídricos. 1997. Disponível em: <http://www.planalto.gov.br/ccivil_03/Leis/L9433.htm>. Acesso em: 22 fev. 2017. 
COMISSÃO MUNDIAL SOBRE O MEIO AMBIENTE E DESENVOLVIMENTO. Nosso Futuro Comum. Rio de Janeiro: Editora da Fundação Getúlio Vargas, 1998.

LEAL, A. C. Gestão das águas no Pontal do Paranapanema-SP. 2000. 300 f. Tese (Doutorado em Geociências). Instituto de Geociências, Universidade Estadual de Campinas, 2000.

Gestão das águas e planejamento ambiental na UGRH Paranapanema - Brasil: Estudos e Desafios. In: Geonorte, Edição Especial, V.4, N.4,2012, p.220 - 238.

RIZK, Cristina Renata; ARAÚJO, Ribeiro d. SILVA, Marcia Aparecida. Esgotamento sanitário: um desafio para o enquadramento de corpos d'água. In: Abordagens em Recursos Hídricos. ARAÚJO Renata Ribeiro de. DI, Cláudio Antonio. DIAS, Leonice Seolin (Orgs.). Tupã: ANAP, 2016. p. 46-62.

SILVA, Suzana de Araújo. Saneamento básico e saúde pública em bacias hidrográficas urbanas: um estudo de caso do Riacho Reginaldo em Maceió (AL). 2014. 110 p. Dissertação (Mestrado em Recursos Hídricos e Saneamento). Universidade Federal de Alagoas. Centro de Tecnologia.

\section{Agradecimentos}

Expressamos, nesse momento, agradecimentos ao colega Eduardo Lima pelo pronto atendimento à nossa solicitação de elaboração do mapa de localização do rio da Chata presente neste texto. 